\title{
Health Education for the Blind: Evaluation of Accessibility of an Inclusive Online Course
}

\author{
Aline Tomaz de Carvalho*, Andréa Soares Rocha da Silva, Ana Fátima Carvalho Fenandes, \\ Lorita Marlena Freitag Pagliuca \\ Universidade Federal do Ceará/PPGENF/UFC, Fortaleza, Brazil \\ Email: ${ }^{*}$ aline.nurse@gmail.com
}

Received 2 August 2014; revised 18 August 2014; accepted 25 August 2014

Copyright (C) 2014 by authors and Scientific Research Publishing Inc.

This work is licensed under the Creative Commons Attribution International License (CC BY). http://creativecommons.org/licenses/by/4.0/

(c) (i) Open Access

\section{Abstract}

This article provides a presentation of the method used to guarantee the accessibility and usability of an online course for blind women. The course discusses breast cancer with a focus on early detection, with a view to granting these women a new form of learning about breast cancer. In this paper, the evaluation of the accessibility of HTML pages was presented by the use of specific software. In addition, it presents the accessibility and usability for blind women in a course in a virtual learning environment. The accessibility evaluation using the software revealed 21 errors. When the blind women accessed the virtual learning environment, sporadic barriers were identified, such as difficulties for registering and using the forum. These were bypassed and the participants defined the access to the online course as satisfactory. This study aims to bring awareness to online education and health professionals about the accessibility of online courses. With regard to health promotion, the importance of this study is clear owing to the lack of educational resources in health for visually impaired people, in addition to the importance of the timeliness of the topic owing to the magnitude of the issue of breast cancer around the world.

\section{Keywords}

Nursing, Blind Persons, Internet, Accessibility, Usability

\section{Introduction}

The number of websites and the amount of information made available on the web have significantly increased, turning the Internet into a fundamental tool for blind people as much as for sighted people. One of the forms through which information is disseminated is online education, which is offered through the Internet. However,

${ }^{*}$ Corresponding author.

How to cite this paper: de Carvalho, A.T., da Silva, A.S.R., Fenandes, A.F.C., \& Pagliuca, L.M.F. (2014). Health Education for the Blind: Evaluation of Accessibility of an Inclusive Online Course. Creative Education, 5, 1559-1566.

http://dx.doi.org/10.4236/ce.2014.516172 
the accessibility of web resources should be developed in a format that provides fast, easy and efficient access to all.

There are about 650 million impaired people around the world, a number that corresponds to ten percent of the world population. They represent the largest minority in the world, and about 80 percent of them live in developing countries (United Nations, 2012).

In view of the large number of disabled people all over the world, the use of different communication tools is extremely important so that, as citizens, they also have access to social goods, particularly health. Thus, considering the different forms that nurse actions take place in order to promote the health of disabled people, countless strategies exist to provide them with information. These include the use of digital information and communication technologies (DICT), mainly the Internet. The Web allows an inclusive style of health education, as these technologies have turned into valuable support tools for the democratization of access to high-quality information, making it possible to overcome inequalities and contributing to inclusion, as well as contributing to health promotion for disabled people (Santarosa, Passerino, Basso, \& Dias, 2007; Becker, Mackert, \& Kang, 2013). Therefore, online educational objects should be planned and developed by respecting certain accessibility criteria.

In its broadest sense, accessibility means building a society of full participation and equality and providing effective interaction among all citizens (Dias \& Passerino, 2009). In regard to web accessibility, it refers to the ability to access the Internet for all people, independent of the type of user, situation or tool (Behar, Souza, Goes, \& Lima, 2008). Through assistive technologies, disabled people should be capable of using the Internet and "navigating" through available content without difficulties or barriers, similar to what is available for non-disabled people (Murphy et al., 2008).

The use of the World Wide Web has gained importance and has penetrated into the activities of daily living, increasingly requiring accessibility (Chalamandaris, Raptis, Tsiakoulis, \& Karabetsos, 2009). The available resources that allow Internet access by disabled people include screen readers, which read the textual content displayed on the computer and then, through voice synthesizers, transform this information into understandable speech. In order to be effective and to be accessed efficiently, the content and design of web contents should be developed into accessible formats, compatible with the functioning of these technologies. Nevertheless, many websites still present barriers when accessed by blind people.

In fact, although assistive technologies have greatly evolved, it is known that the difficulties for blind people in using the information on the Internet continue. To overcome this, the content projected for the web needs to comply with a pattern of accessibility. International organizations like the World Wide Web Consortium (W3C) create the Web Accessibility Initiative (WAI) in an attempt to guarantee accessibility to disabled people or for those who access the web under other conditions affected by the environment, the equipment, the navigator or by tools.

Similarly, it is very important that health education and communication content are constructed in an accessible format, so as to guarantee that disabled users are fully able to obtain the resources and to use them whenever necessary. Therefore, it is fundamental to understand that accessibility goes beyond the rupture of architectonic barriers, the breaking of attitudinal, communication and transportation barriers, and that is linked with the concept of universal design. Anyone thus has the right to enter it, remain in it and enjoy all its goods (Behar, Souza, Goes, \& Lima, 2008).

Hence, as a result of technological advances, nursing also uses these new trends in health education. Therefore, creative thinking is needed in order to guarantee that nursing can also offer its customers the benefits of this new healthcare technology (Kane, 2010). Nurses need to create inclusive educational materials, based on the concept of universal design, to have access to all people.

It should be highlighted that, among the diseases that affect women, breast cancer is a condition that has a global dimension. Actions to counter the mortality caused by this disease are put in practice through early detection tests, which represent a relevant theme for health education. Some groups of women are considered vulnerable, though, due to a lack of information or to a predisposition, and these include blind women. Earlier studies affirm that information about cancer is still lacking in this group, which can increase the group's mortality rate (Pagliuca \& Costa, 2005; McCarthy, 2006).

In compliance with health promotion strategies, nurses can act to secure the education of blind women through an accessible online course about breast cancer and through the early detection of the disease. Therefore, the intent is to offer updated and accessible content about this subject in the form of inclusive education, in an 
attempt to minimize breast cancer-related mortality within the referred group of women.

The objective of this study is to evaluate the accessibility and usability of a previously developed online education course about breast cancer, accessible to blind women and focused on early detection.

All standard paper components have been specified for three reasons: 1) ease of use when formatting individual papers; 2) automatic compliance to electronic requirements that facilitate the concurrent or later production of electronic products; and 3) conformity of style throughout a journal paper. Margins, column widths, line spacing, and type styles are built-in; examples of the type styles are provided throughout this document and are identified in italic type, within parentheses, following the example. Some components, such as multi-leveled equations, graphics, and tables are not prescribed, although the various table text styles are provided. The formatter will need to create these components, incorporating the applicable criteria that follow.

\section{Method}

This is a methodological study based on the construction of an online course. The reference framework adopted was the Development Model of Digital Educative Material, which involves the following five phases: Analysis and Planning, Modeling (Conceptual, Navigation and Interface), Implementation, Assessment and Maintenance and Distribution (Falkembach, 2005). This article is based on the results obtained in the implementation phase, when the accessibility and usability tests were undertaken as described below.

In the implementation phase, the initial tests were done and the errors were removed. In this phase, a trained website construction and hosting professional cooperated with the research team. The loading and speed of the sites, the correct association between links and websites and the accessibility criteria for disabled people were tested. At that point, the objective was to make the online course easily accessible, in accordance with the proposed structural model, for any and all kinds of users.

The data were collected between August and October 2012 in two distinct phases, which are the Accessibility Assessment of HTML pages and the Accessibility and Usability Assessment of the Virtual Learning Environment.

\subsection{Accessibility Assessment of HTML Pages}

During this phase, the Online Breast Health Course was assessed: its content and appearance had been previously validated during a master's thesis project. Initially, the course consisted of 15 HTML pages with four image files, one audio file and three forms produced with the Forms tool in Google Drive ${ }^{\circledR}$. These were submitted to the accessibility assessment process.

The software Avaliador e Simulador para a Acessibilidade de Sítios (ASES) was used to initially test the accessibility of the classes (Brasília, Brazil). This software reads the Hypertext Markup Language (HTML) code of the requested pages (Brasil, 2011) and verifies whether the page was constructed in accordance with international accessibility rules, as determined by the Web Content Accessibility Guidelines (WCAG).

The HTML pages were assessed before their inclusion in the virtual learning environment, so that the assessment would not additionally consider the VLE. Therefore, the HTML pages were hosted on a private server and, to use ASES, the option file was chosen among the levels to assess. The file present on the server was located and the evaluation was undertaken in accordance with the WCAG standards. The accessibility errors indicated by that software were corrected in accordance with the suggestions provided.

\subsection{Accessibility and Usability Evaluation of Virtual Learning Environment}

In this phase, the participation of two blind users was requested to inspect the accessibility and usability of the virtual learning environment. The participants or evaluators verified the accessibility and usability barriers in accessing the environment and the use of its tools. They were invited to attend a specific laboratory, used individual computers with an NVDA ${ }^{\circledR}$ screen reader to access the virtual learning environment and identified possible barriers between the initial registration of new users and their participation in interactive activities like the forum.

A series of minimal tasks were dictated, which they were expected to accomplish. As the proposed activities were performed, their statements were transcribed in order to register any comments related to difficulties, suggestions or positive points of the environment. 
The criteria for selecting the two evaluators of the virtual learning environment's accessibility and usability were: being blind, being over 18 and having at least intermediary computer and Internet usage skills through assistive technologies.

\subsection{Data Analysis}

The results obtained through the ASES ${ }^{\circledR}$ assessment were organized into tables. In the accessibility and usability assessment of the virtual learning environment, the answers and comments made during the assessment were grouped based on the tasks performed and analyzed according to the relevant literature.

The ethical aspects of research involving human beings were respected, in accordance with the principles of the Helsinki Declaration. The participants received information about the nature, purpose and risks related to the study and freely signed Informed Consent Forms.

\section{Results and Discussion}

\subsection{Accessibility Assessment of HTML Pages}

To guarantee the accessibility of the HTML pages before they were loaded onto the virtual learning environment, the ASES ${ }^{\circledR}$ software was used to perform the assessment based on the relevant guidelines (W3C, 2008). This led to the identification of 21 accessibility errors (Table 1).

In order to develop accessible websites, various components need to interact in this process, including assistive technologies, users and the assessment tools (W3C, 2014). Hence, following international standards and applying tests are important steps that web developers need to perform.

Currently is used the Web Content Accessibility Guidelines 2.0 (WCAG 2.0), which determines that any web resource constructed in an accessible format should be: Perceivable: the information and user interface components should appear before the users so that they can perceive them; Operable: the user interface and navigation components should be operable; Understandable: the information and operations of the user interface need to be understandable; Robust: the content needs to be robust enough to be interpreted and used by a wide range of users and their different assistive technologies (W3C, 2008).

Among all of the accessibility errors ASES indicated, what most stood out was the lack of identification of the main language, observed on all pages. This type of error disregards the identification of the main language used. This type of error violates the "Understandability" principle of WCAG 2.0. That principle is intended to ensure that users can understand the information the website contains and its operation (W3C, 2008).

In an accessibility assessment of 54 websites, it was determined that the majority of them couldn't have the main language identified. Identifying the predominant language of the content benefits visually impaired users who use screen readers, as they will immediately receive the information if the language is appropriate to their understanding. This grants them freedom to choose whether to continue navigating the page, which is directly related to usability, that is, to the user satisfaction when navigating across websites (Ferreira \& Cianconi, 2011).

In class 1 , it was possible to identify the need to separate adjacent links. This was due to the fact that the links "Back" and "Next", which respectively lead to the previous and next pages, were displayed next to one

Table 1. Presentation of erros and E-Mag and WCAG principles that were disobeyed. Fortaleza, 2012.

\begin{tabular}{|c|c|c|c|}
\hline \multirow{2}{*}{ Error } & \multicolumn{3}{|c|}{ Recomendations } \\
\hline & EMAG & WCAG & $\mathrm{N}^{\mathrm{o}}$ \\
\hline Identification of Main Language Used & Content/Information & Understandable & 14 \\
\hline Allows text redimensioning without loss of functionality & Presentation and design & Perceivable & 2 \\
\hline Offers a descriptive and informative title for the site & Content/Information & Operable & 2 \\
\hline Provides a text alternative for the images & Content/Information & Perceivable & 1 \\
\hline Separates adjacent links & Marking & Perceivable & 1 \\
\hline Does not use elements W3C considers outdated & Marking & Robust & 1 \\
\hline
\end{tabular}


another, which hampers the understanding of users who use a screen reader, as the reading is done without intervals or pauses. Not all screen readers are able to distinguish links that are displayed very close to one another, which can cause difficulty in understanding when one link ends and the next begins. One solution for this barrier would be to insert a character between the links that does not belong to either, like a vertical bar, for example (Web Accessibility in Mind, 2013).

In class 2, the lack of a title on the page that displayed a questionnaire created using the tool Forms in Google Drive ${ }^{\circledR}$ was identified. The software suggested creating a title for this questionnaire using HTML, to allow the user to identify the presence of the form and thus operate it satisfactorily.

Another frequently ignored principle was Perceivable, with four errors. Two of them were related to the media file corresponding to the podcast about female breast anatomy in class 2 . The evaluating software determined that the image of the audio resource had not been described, and that its aspect ratio was given in absolute terms instead of a percentage, which could cause a distorted image when widening the screen. This media resource was also considered outdated by W3C, which violates the Robustness principle and suggests using other, more up-to-date, audio resources (W3C, 2008).

The lack of description of non-textual elements does not imply that users of screen readers do not perceive the image displayed on the website. Although it is an audio device, these files are represented by an image of an audio resource and this should be described to visually disabled people. One study evaluated the accessibility of school websites in Texas and found that most accessibility errors were related to the lack of description of non-textual elements (May \& Zhu, 2010). Similarly, a study that evaluated public websites in Greece found that the predominant error was the lack of description of these elements (Basdekis, Klironomos, Metaxas, \& Stephanidis, 2010).

Concerning absolute figures to format images, their use on a website means it is impossible to widen the screen without distorting the image. At the same time, this hampers the visualization of the image on older computers with screens of lower resolution or on mobile devices, as no adaptation is available to reduce the image to the size of the monitor or display. The use of percentage figures to format pages, images or tables allows their adaptation to larger or smaller sizes without losing quality or any of their elements. Two hundred percent is considered a reasonable adaptation that can support a wide range of designs and layouts (W3C, 2014).

On the final page of the Online Breast Health Course, which also displayed the questionnaire that was formatted in the Forms tool of Google Drive ${ }^{\circledR}$, an error was indicated because the page did not allow the resizing of the text without loss of functionality. This form had been formatted in absolute instead of percentage aspect ratio of height and width. In addition, another error in that questionnaire was the lack of a title, making it difficult and confusing for the user to understand the presence of the form and to use it.

In order to give blind users a pleasant website navigation, titles should be created for all pages. So the users can understand where they are at every moment. This also applies to the questionnaires included, which should be conceived in a logical and consistent manner, with a general description in the title and the description of all fields (American Foundation for the Blind, 2014). If not, due to a very long, confusing or missing title, the user may not be able to utilize the resource (Yesilada, Brajnik, \& Harper, 2011).

After correcting the accessibility barriers indicated by ASES, the HTML pages of the Online Breast Health Course were considered fully accessible. They could then be used by blind people but also by people with different kinds of disabilities. Nevertheless, the software evaluation does not guarantee full accessibility or usability, until it is actually assessed and evaluated by visually impaired users.

\subsection{Accessibility and Usability Evaluation of the Virtual Learning Environment}

Two blind women (DV1, DV2) participated in this phase. Both of them are skilled computer users. DV1 is 25 years old. She's and a Master's student with advanced computer and Internet usage skills. DV2 is 18 years of age. She is on secondary school at a specialized institution for the blind and she has intermediate computer and Internet skills.

In the course of the proposed activities, their considerations and any difficulties that arose were written down. At the end, they were invited to report on the experience as a whole.

To evaluate the web accessibility and its components, within the context of an online course, various methods can be used. Some of them include the request for users to navigate through the environment and identify any 
difficulties. The test involving users may or may not be accomplished formally, and they are invited to access the website while their behavior is observed (Brajnik, Yesilada, \& Harper, 2012). In general, during usability tests, the users are observed while they accomplish requested tasks (Evans \& Douglas, 2008). Good usability goes beyond the user's subjective satisfaction and includes the effective understanding of the tasks performed and the users' cognitive processes when confronted with the tasks (Staggers, 2010).

Asking the users to express the difficulties faced while navigating through the virtual learning environment allows a better understanding of their individual limitations and how this environment can be further adapted in response to that. An earlier study evaluated a website with the help of visually impaired users, noting the importance of the user participation in the evaluation process. The study defined their participation as essential to a process with multiple opinions, in order to achieve a new accessible web (Chandrashekar \& Hockem, 2009).

\subsubsection{Homepage of the Virtual Learning Environment: Access and Registering}

According to the users' reports, completing the form for new users caused the largest number of barriers, and, therefore, required more time. The first barrier described by the blind women was the lack of identification of the registration process (at its beginning), as the screen reader remained silent.

As the visually impaired users access the form, they need to interact with it. So that the navigation arouses interest and they continue the completion process. Therefore, the cursor should be automatically directed to the first field of the form. All other fields should be organized hierarchically and grouped in categories (personal data, school data, etc.). Each one should have a textual description, so that blind people can hear in what field they are (Evans \& Douglas, 2008). Next, the users indicated difficulties finding the Online Breast Health Course. When placing the cursor in the field to choose the course, a long list of available courses is displayed on top of the form. As the list was long and depended on scrolling the mouse, searching for the Online Breast Health Course was impossible, unless the users inserted the course's initial letter in the field.

Using keywords represents an alternative to the use of the mouse, especially for visually impaired people. However, navigating with the help of the keyboard can be difficult, if one doesn't have predefined access keys (Nóbrega, 2011). In this study, as the users attempted to advance in the completion of the registration, the cursor returned to the first field. This happened because most forms are developed to be completed with the use of the mouse and keyboard, or else they need indications on how they can be filled out (Porta, 2008).

Visually impaired people mainly use the key "TAB" to advance through computer activities, besides other keyboard resources. This is not accepted by mouse-controlled forms, which can be an obstacle to their completion. Considering these difficulties, online education activities can turn into frustrating or intimidating tasks for visually impaired people, as most activities in this modality depend on the use of the mouse (Guercio, Stirbens, Williams, \& Haiber, 2011).

\subsubsection{Access to the Forum and Sending a Message}

Another negative aspect indicated by the blind women was accessing the forum and sending a message. When they reached the box to edit the text, once again the screen reader failed to present the editor to the users, who became disoriented as to how to locate the field to write the message.

Forums are objects of interactivity and information exchange in a virtual learning environment. Which favor learning and the exchange of experiences among the participants. When including a forum in an environment, however, this tool should receive a label so as to enable the blind user to identify where it is. Both users of the present research determined that the problems they identified would have been minimized through a preliminary step-by-step orientation on accessing the forum and sending a message.

\subsubsection{Access to the Online Breast Health Course (BH) Classes}

In regard to accessing the BH classes, the users DV1 and DV2 did not mention any difficulties, which may demonstrate the absence of accessibility and usability barriers in this part of the virtual learning environment.

\subsubsection{Perceptions of the Experience as a Whole}

In general, the two users considered the access to the environment satisfactory, with sporadic accessibility and usability considerations. It was clear, however, that the blind women experienced certain difficulties that would have caused them to give up participating in the course at the beginning, specifically when registering as a new user. The same was reported in other studies, where activities undertaken by blind college students in an online 
course were described as totally inaccessible (Fitchen et al., 2009).

Adjustments are needed in the virtual learning environment so that blind people can enjoy the benefits of this online course with the same satisfaction and ease as people without disabilities, therefore making it more welcoming (Nóbrega, 2011; Batista \& Mollica, 2014). Through these means it is possible to achieve an inclusive learning environment, which is apt to integrate all students in the same educational process.

\section{Conclusion}

The accessibility evaluation with the help of the evaluator software revealed 21 accessibility errors, which were all corrected. The assessment of the virtual learning environment with blind users, however, presented some barriers, such as the difficulty to register for the course and to use the forum. These difficulties were surpassed and the users who participated in the test defined the access as satisfactory.

Besides the phases mentioned throughout the present work, the Online Breast Health Course went through the validation of its content and pedagogical aspects, which were not discussed in this paper. However, it is worth noting that for the course to be finally validated, it must pass through the users' evaluation once they've completed all the modules.

The present study can reach professionals from different areas who are interested in accessibility on the web, as well as in the development of inclusive online courses and their assessment process, since evaluation methods and evaluative software were here presented. Hence, it is important to highlight that this study can raise awareness to professionals in online education about accessibility issues of virtual learning environments, in general.

This study is clearly important to the field of health promotion, considering the lack of health education resources for people with visual and other impairments. Furthermore, its theme is of extreme importance, due to the magnitude of breast cancer incidents around the world.

\section{Acknowledgements}

This study was made possible through a grant from the Coordination of Improvement of Higher Education Personnel (CAPES).

\section{References}

American Foundation for the Blind (2014). Tips and Tricks to Improve Web Accessibility. http://www.afb.org/section.aspx?FolderID=2\&SectionID=4\&TopicID=167\&DocumentID=1453

Basdekis, I., Klironomos, I., Metaxas, I., \& Stephanidis, C. (2010). An Overview of Web Accessibility in Greece: A Comparative Study 2004-2008. Universal Access in the Information Society, 9, 185-190.

http://link.springer.com/content/pdf/10.1007\%2Fs10209-009-0166-z.pdf

Batista, H., \& Mollica, M. (2014). Public Virtual Rooms of Learning and Social Identity: An Emerging Technology Resource. Creative Education, 5, 630-635. http://dx.doi.org/10.4236/ce.2014.58074

Becker, H., Mackert, M., \& Kang, S. J. (2013). Using an E-Health Intervention to Promote the Health of Cancer Survivors with Preexisting Disabling Conditions. Computers, Informatics, Nursing, 31, 107-114.

http://www.ncbi.nlm.nih.gov/pubmed/23254367

http://dx.doi.org/10.1097/NXN.0b013e3182771895

Behar, P. A., Souza, E. K., Goes, C. G., \& Lima E. M. (2008). A importância da acessibilidade digital naconstrução de objetos de aprendizagem. Renote, 6, 2. http://seer.ufrgs.br/renote/article/view/14459.

Brajnik, G., Yesilada, Y., \& Harper, S. (2012). Is Accessibility Conformance an Elusive Property? A Study of Validity and Reliability of WCAG 2.0. ACM Transactions on Accessible Computing, 4, Article 8. http://users.dimi.uniud.it/ giorgio.brajnik/papers/taccess2012.pdf

Brasil (2011). Ministério do Planejamento, Orçamento e Gestão. Secretaria de Logística e Tecnologia da Informação. Departamento de GovernoEletrônico. eMag-Modelo de Acessibilidade em Governo Eletrônico. Brasília: Ministério do Planejamento, Orçamento e Gestão. 13 Web Content Accessibility Guidelines (WCAG) 2.0. W3C.

http://www.governoeletronico.gov.br/acoes-e-projetos/e-MAG http://www.w3.org/TR/WCAG/

Chalamandaris, A., Raptis, S., Tsiakoulis, P., \& Karabetsos, S. (2009). Enhancing Accessibility of Web Content for the Print-Impaired and Blind People. Computer Science, 58, 89.

Chandrashekar, S., \& Hockem, S. (2009). Online Access, Participation and Information Credibility Assessment. Proceedings 
of the Science and Technology for Humanity (TIC-STH), IEEE Toronto International Conference, Toronto, 26-27 September 2009. http://dx.doi.org/10.1109/TIC-STH.2009.5444397

Dias, C. O., \& Passerino, L. M. (2009). Uma proposta de metodologia para adaptação de OA usando critérios de acessibilidade. Renote, 7. http://seer.ufrgs.br/renote/article/view/13585

Evans, S., \& Douglas, G. (2008). E-Learning and Blindness: A Comparative Study of the Quality of an E-Learning Experience. Journal of Visual Impairment \& Blindness, 102, 77-88.

Falkembach, G. A. M. (2005). Concepção e Desenvolvimento de Material Educativo Digital. Renote, 3.

Ferreira, G. A., \& Cianconi, R. B. (2011). Acessibilidade dos deficientesvisuais e cegosàsInformações de Bibliotecasuniversitáriasna web. Informação \& Sociedade, 21, 151-163. http://www.ies.ufpb.br/ojs/index.php/ies/article/view/10248

Fitchen, C. S., Asuncion, J. V., Barile, M., Ferraro, V., \& Wolforth, J. (2009). Accessibility of e-Learning and Computer and Information Technologies for Students with Visual Impairments in Postsecondary Education. Journal of Visual Impairment \& Blindness, 103, 543-557.

Guercio, A., Stirbens, K. A., Williams, J., \& Haiber, C. (2011). Addressing Challenges in Web Accessibility for the Blind and Visually Impaired. International Journal of Distance Education Technologies, 9, 1-13. http://dx.doi.org/10.4018/IJDET.2011100101

Kane, K. (2010). eHealth and Nursing Informatics. British Journal of Community Nursing, 15, 157. http://dx.doi.org/10.12968/bjcn.2010.15.4.47350

May, S., \& Zhu, Q. (2010). A Web Accessibility Assessment on the Texas Public School System. Universal Access in the Information Society, 9, 87-96. http://dx.doi.org/10.1007/s10209-009-0153-4

McCarthy, E. P., Ngo, L. H., Roetzheim, R. G., Chirikos, T. N., Li, D. L., Drews, R. E., \& Iezzoni, L. I. (2006). Disparities in Breast Cancer Treatment and Survival for Women with Disabilities. Annals of Internal Medicine, 145, 637-645. http://dx.doi.org/10.7326/0003-4819-145-9-200611070-00005

Murphy, E., Kuber, R., McAllister, G., Strain, P., \& Yu, W. (2008). An Empirical Investigation into the Difficulties Experienced by Visually Impaired Internet Users. Universal Access in the Information Society, 7, 79-91. http://dx.doi.org/10.1007/s10209-007-0098-4

Nóbrega, G. C. (2011). Acessibilidade aos conteúdos visuais em ambientes virtuais de aprendizagem. Revista Brasileira de Tradução Visual, 9.

Pagliuca, L. M. F., \& Costa, E. M. (2005). Tecnologia educativa para o autoexame das mamas em mulheres cegas. Revista da Rede de Enfermagem do Nordeste, 6, 77-85.

Porta, G. (2008). Formulários em uma Web para todos. http://acessibilidadelegal.com/13-formularios.php

Santarosa, L. M. C., Passerino, L., Basso, L. O., \& Dias, C. O. (2007). Acessibilidade em Ambientes de Aprendizagem por Projetos: Construção de espaçosvirtuais para inclusão digital e social de PNEEs. Renote, 5.

Staggers, N. (2010). The Rapidly Emerging National Interest in HIT Usability. OJNI Online Journal of Nursing Informatics, 14, 1-4. http://ojni.org/14_3/Staggers.pdf

United Nations (2012). Factsheet on Persons with Disabilities. http://www.un.org/disabilities/default.asp?id=18

Web Accessibility in Mind (2013). Designing for Screen Reader Compatibility. http://webaim.org/techniques/screenreader/

Yesilada, Y., Brajnik, G., \& Harper, S. (2011). Barriers Common to Mobile and Disabled Web Users. Interacting with Computers, 23, 525-542. https://www.escholar.manchester.ac.uk/uk-ac-man-scw:147728

http://dx.doi.org/10.1016/j.intcom.2011.05.005 
Scientific Research Publishing (SCIRP) is one of the largest Open Access journal publishers. It is currently publishing more than 200 open access, online, peer-reviewed journals covering a wide range of academic disciplines. SCIRP serves the worldwide academic communities and contributes to the progress and application of science with its publication.

Other selected journals from SCIRP are listed as below. Submit your manuscript to us via either submit@scirp.org or Online Submission Portal.
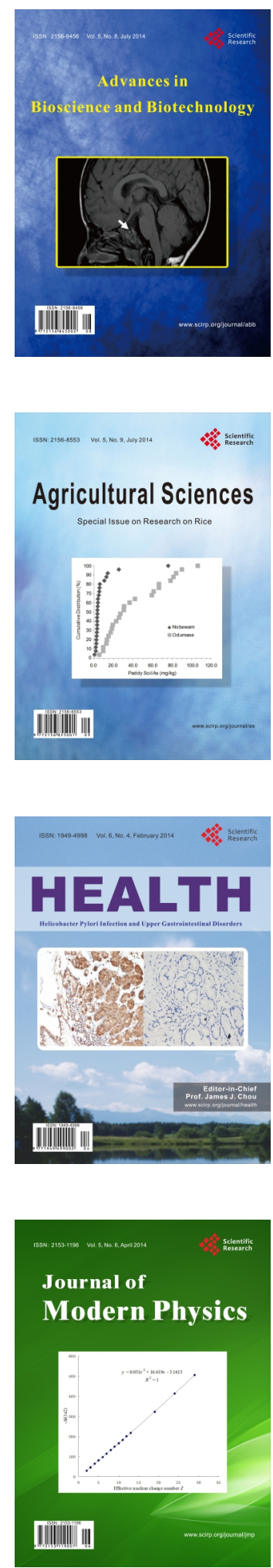
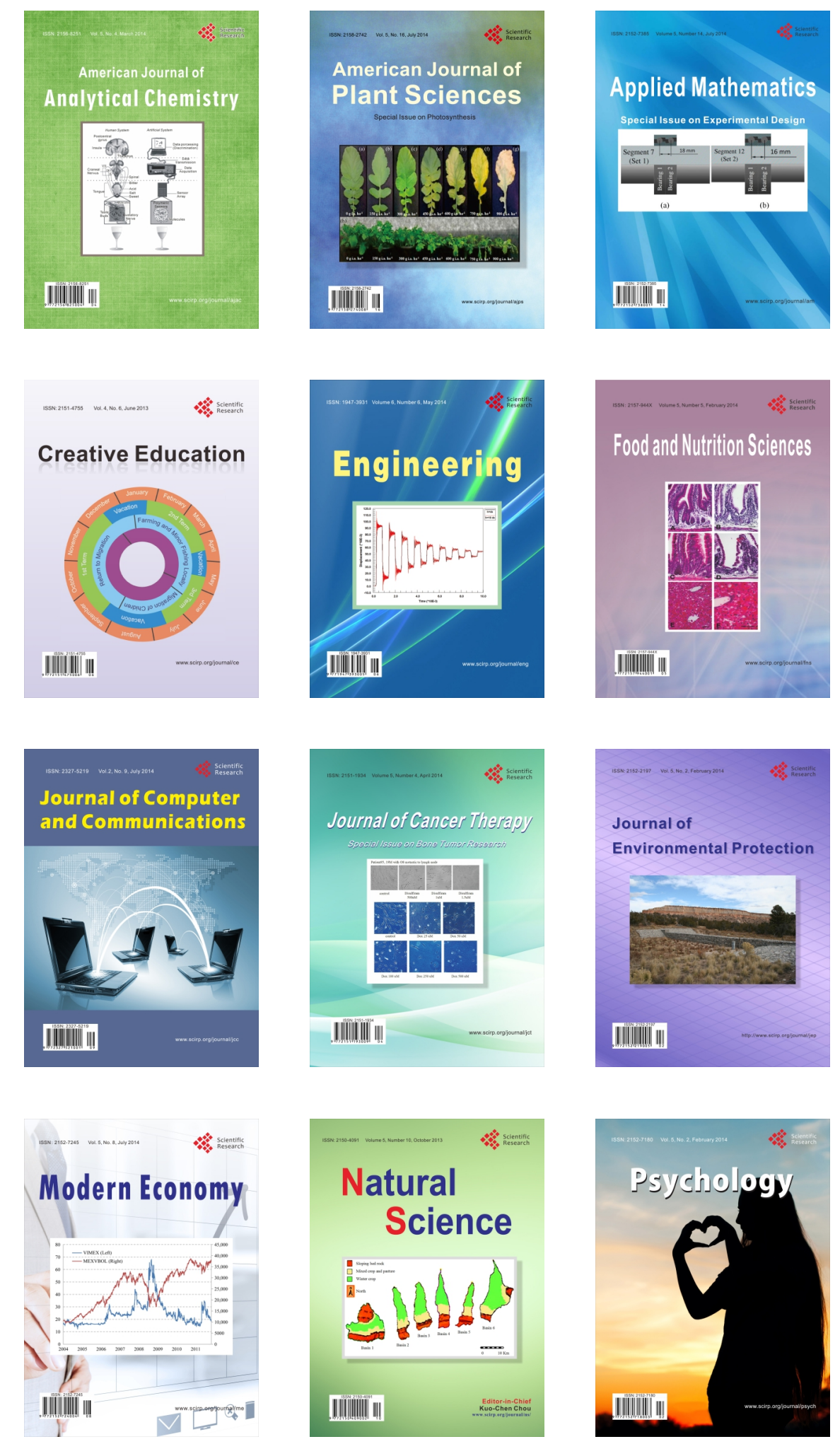